\title{
Upbringing in a digital world: Opportunities and possibilities
}

\author{
Alona Forkosh Baruch1', Ola Erstad²
}

\begin{abstract}
In our article, we refer to the interrelation between upbringing and education, within the context of an emerging paradigm of upbringing as a new construct. First we discuss upbringing in the digital era. Then, we state the main concerns involving this theme, which we label as key challenges for upbringing in the digital world. This is followed by the main challenges for upbringing in the digital era: an ecological (environmental) challenge, an intergenerational and intercultural challenge, the challenge of creating an educational continuum, and the challenge of upbringing digital citizens as informed adults, as well as possible ways of tackling these challenges. Finally, we suggest recommendations to policymakers, researchers and practitioners for each of the challenges and end with some conclusions on this theme.
\end{abstract}

Keywords: upbringing, digital world, digital era, opportunities, challenges

\section{Introduction}

We are living in a world where characteristics of upbringing are changing due to the saturation of technology and information in contemporary societies, in which technological developments pose physical, cognitive, emotional, social and ethical challenges to human society at large and to the education milieu specifically. Hence, the main objective of this article is to present recent advances of research and development in this field, focusing on technological developments and sociocultural dynamics of social constructs and new opportunities for creative practices. There is a need to explore children and youth as agents of change using diverse technologies. Increasingly, at an early age young children are becoming accustomed to technologies as part of their upbringing, in play and learning. This level of familiarity has implications for development and trajectories of learning, and for children consequently becoming active involved citizens of the world. All of these developments have implications for policy and practice.

\section{Upbringing as a new construct}

Upbringing and education are interrelated. In a traditional context, upbringing is mostly referring to parental competencies and the home setting, while education and pedagogy refer to formal teaching and learning. However, in the digital era,

\footnotetext{
1 alonabar@levinsky.ac.il, Levinsky College of Education, Tel Aviv University, Israel

2 ola.erstad@iped.uio.no, University of Oslo, Norway
} 
we face an emerging paradigm of upbringing as a new construct, fundamentally different than in prior generations.

The traditional definition of upbringing is quite narrow, including mostly the family perspective, e.g., "the way in which you are treated and educated when young, especially by your parents, especially in relation to the effect that this has on how you behave and make moral decisions" (Cambridge Dictionary), or "the treatment and instruction received by a child from its parents throughout its childhood" (Encyclopedia.com). A wider definition can be found as well, e.g. "the care and training of young children or a particular type of such care and training" (Dictionary.com). When discussing the term upbringing, the concepts that come to mind range from bringing up, rearing, raising and breeding, to caring, fostering and tending. Additional concepts may include facilitating tolerance (Grigorev, Grinshkun \& Lvova, 2014) and involve developing media literacy skills and competencies (Livingstone, 2004) or digital literacies in general (Sefton-Green, Marsh, Erstad \& Flewitt, 2016).

Challenges of upbringing in a digital world are influenced by social and cultural changes worldwide. International processes of globalization in several domains, accompanied by technological advancements, transform our lives and demeanor in all aspects of our lives (Voogt, Erstad, Dede \& Mishra, 2013). These processes raise yet another issue, namely: what is the purpose of K-12 schools in $21^{\text {st }}$ century societies, particularly with the growing role of serendipitous and ubiquitous learning beyond school? Digital technology is transforming education rapidly, towards e-learning and mobile learning in ways that question traditional schooling. In addition, the purpose of many schools may not truly reflect best learning practices for young people in contemporary societies, e.g., 21 st century skills, aiming for better and relevant education (Kaufman, 2013).

\section{Digital childhood and youth - a constant transition}

Twenty-first century skills may clash with traditional schooling guided by standards. However, schools nowadays are more prone, formally or informally, to developing students as individuals and exploring directions such as creativity, as adjunct to ICT literacy to leverage lifelong skills that are vital to future accommodation to the digital era, e.g., leadership, ethics, accountability, 
adaptability, productivity, interpersonal skills and social responsibility. Media and ICT skills are daily necessities, enabling children to search, organize, evaluate and produce information using technology. This implies that technology is not merely gadgets and devices, but also engaging in the handling of information (Kaufman, 2013).

One key aspect of media culture today, compared to only a decade ago, is the pervasiveness of media, especially due to the development of mobile technologies (Damásio, Henriques, Teixeira-Botelho \& Dias, 2015). Very few spaces or places today have no media use going on. There are, of course, both concerns and prospects in line with these developments. On one hand, the growing usage of mobile technologies (e.g., tablets, smartphones) allows instant and ubiquitous access to the Internet via portable devices that even children of a young age are able to manage and operate easily, e.g., download content. Moreover, users from a young age learn informally how to generate content of their own and share this content by uploading it online, which creates a new participatory culture (Bond, 2014). Also, mobile technology is changing the way children are learning in ways unimaginable in former generations (Druin, 2009). On the other hand, this new trend implies the need for parents and educators to verify that children and youth utilize these devices and opportunities wisely.

Young children around the globe are growing up in a digitalized world, yet little is known about the ways in which they develop 'emergent digital literacy' or ways of meaning making (Marsh, 2015) in homes and communities. There is evidence that suggests online and offline boundaries are fluid for contemporary children, as their play activities cross physical and 'virtual', material and immaterial domains in fluid and dynamic ways (Merchant et al., 2013; Marsh et al., 2015). However, there is still much to understand about what this relationship looks like and means in terms of broader cultural practices (Sefton-Green, Marsh, Erstad \& Flewitt, 2016; Holloway, Green \& Livingstone, 2013). Research has found that most children by the age of two use a tablet or laptop. Approximately a third of children aged under five who have access to tablets in their home possess their own personal tablet (Marsh et al., 2015). More than one of third children under five years old are using mobile phones to access apps and games; for example, online games like Minecraft have engaged young children in global networks. Touch screen technologies herald a digital sensory revolution, where new touch-sensitive 
interfaces are set to reconfigure the interaction between person and artifacts. These technological developments call into question the centrality of language in communication and literacy practices, and have inescapable implications for young children, not only for their early literacy development and play, but also in terms of how education can help to equip today's young citizens for a digitally connected future (Sefton-Green, Marsh, Erstad \& Flewitt, 2016).

Furthermore, the age-specific use of digital media is often more complex than the impression gained from public discourse. On certain social networking sites, age groups in their 20s and 30s are even greater consumers than youth, since younger age groups switch to new platforms more easily (Erstad, 2016). However, there are certain aspects of the contextual embedding that these media have for youth rather than for adults that seem different, especially in terms of how digital media seem to play a role in identity constructions among youth (Boyd, 2014; Hershkovitz \& Forkosh Baruch, 2017; Vasbø, Silseth \& Erstad, 2014). As such, it is important to define digital youth by examining the emerging practices in digital media use and how these change over time. In this way we gain a better understanding of the development of social patterns of media use, how they are distributed among the population as a whole, and the social, cultural, and educational implications they might have.

Another growing body of knowledge refers to the term "digital language", encompassing the necessary digital skills for young people to adapt to the current digital world and to function competently within its boundaries. This includes the ability to program as a means of problem solving, often addressed as computational thinking (CT). This notion describes a way of thinking which involves problem solving, design thinking and understanding phenomena by utilizing concepts from the world of computer science (Pinto-Llorente et al., 2017).

Studies conducted with children even at a young age show evidences of the importance of ICT for developing higher order thinking skills. For example, the use of robotic software influenced students' ability to solve problems in a programming language (Elkin, Sullivan \& Bers, 2014; Marsh et al., 2016; Mayerové, \& Veselovská, 2017). These studies show that robotics can be integrated and used as educational tools for empowering skills of young children, even in primary schools, and even in settings previously excluding technology 
altogether. Findings establish the benefits of teaching ICT in classrooms from an early age. Moreover, students exhibited engagement, enthusiasm and motivation when experiencing tasks, manipulating components, constructing and programming the 3D models ((Pinto-Llorente et al., 2017; Buitrago Flórez et al., 2017). Through these activities, students experienced authentic situations and practiced coping with real-world problems through reflection on their actions and attempts to solve them (Pinto-Llorente et al., 2017).

As emphasized, technological, electronic, computational and screen-based tools can coexist in children's lives, together with traditional non-digital devices and tools. Children, even of a young age, may gain academic, intellectual, social and emotional benefits when experiencing several types of digital and non-digital media (Alper, 2013).

\section{Key challenges for upbringing in the digital world}

Based on the new construct of upbringing in the digital world, as detailed above, and on the transition stage which childhood and youth are experiencing as a vital characteristic of the digital era, we defined four key challenges for the field of education.

\section{Challenge 1: Ecological (environmental) challenge: awareness of family, community and peers of new opportunities and risks of upbringing in a digital world}

The digital world defines a new model of interaction between a child, his/her family and relatives, friends, schools and teachers, and the environment. Each of these relationships must be examined and studied, thereby identifying the essential features relevant to upbringing in the digital era (Fox \& Diezmann, 2017). These interactions play a fundamental role in regulating the flow of information, and in monitoring and assisting in information management from a very young age. Digital technologies are rapidly penetrating into our lives. The technological forms are becoming more natural in their interfaces, and an integral part of the ecological system. Consequently, the skills required from children as well as adults are also transforming, emphasizing not only technical aspects but 
also life-skills (Terreni, 2010) and socio-cultural practices (Aubrey \& Dahl, 2014).

However, de facto there seems to be a 'digital disconnect' between homes and educational institutes regarding experiences children have with technologies (Levin, Arafeh \& Rainie-Director, 2002). Children learn to use technologies rather naturally within home contexts; however, educational settings fail to connect with the usage of technology at home. This disconnect is related to the need to emphasize children's digital literacies and use technologies in educational settings the way they are used at home (Aubrey \& Dahl, 2014; Barnyak \& McNelly, 2015). Moreover, we are experiencing shifts from narrowly defined explorations of children's interactions with specific resources, towards broader investigations of the role and position of technologies in children's early learning experiences. Research contributes to our understanding of how technologies are integrated in the more complex ecological system of children's early learning, nowadays more than in past generations, due to the implementation of digital media (Arnott, 2016). The usage of information technologies from an early age is being constantly explored, thereby broadening focus on technology use in formal and informal educational settings and facilitated by broader definitions of technologies (Arnott, 2013; Plowman, 2015). As a result of these explorations, researchers and practitioners may better understand the role of technologies in children's lives.

The main task for this challenge is to ensure the advantages of opportunities in the digital era (e.g. connectivity, awareness), and to be able to control the negative impact of the digital environment through joint endeavors that include all stakeholders (e.g. parents, schools and the community as a whole). Young children can be supported directly and formally by practitioners and also by parents in developing a digital learning environment in preschool and at home. Research has shown that learning in a digital context can produce measurable gains even at an age as early as 3 years old (Plowman, 2015). However, there are concerns regarding the issue of technology advancing or rather inhibiting the child's development. Children's often passive consumption of technology is discussed in much of the existing literature, identifying concerns regarding technologies ranging from television to desktop computer and tablets and other mobile devices. However, a new generation of technologies with tangible 
interfaces facilitates shifts between digital and non-digital resources and interfaces (Plowman et al., 2012; Siraj-Blatchford \& Brock, 2016).

Technology enables interactions that assist children in developing future skills; nowadays, the emergence of technologies such as the Internet of Things requires us to reconsider ways of connecting technology to relevant context on a day-today basis (Plowman, 2016). Mobile phones and devices, laptops and tablets are constantly connecting us to each other as well as to information. Wearables as well as microchips are rapidly being embedded into fabrics and possibly into our bodies (Donald, 2014).

Consequently, children should be taught to independently formulate criteria for determining the usefulness of a given technology. The learning process in the digital era should include cultural traditions and diversity, thereby acknowledging the influence and traditions of the community, alongside global trends, involving the community at large. Formation of alternative communities for parents and children may establish collaboration between all involved in upbringing, enabling facilitation of joint educational projects.

\section{Challenge 2: Rethinking intergenerational and intercultural dynamics of family and educational institutes linked to upbringing}

In today's world, in addition to interpersonal differences in communication, behavior and interaction of members of different generations and cultures, there are also commonalities as a result of digital media penetrating our lives. New points of intersection between the elderly and young people, as well as people with different cultural traditions, are related to digital technologies. Hence, to begin a discussion referring to any gap in digital competencies and skills, the term that comes to mind almost naturally is that of "digital natives" (Prensky, 2001). However, there seems to be no one accepted definition of this concept, varying among individuals, societies, regions and nations, as well as attaining different meaning over time. Furthermore, in addition to age, which is the most common variable considered when differentiating digital natives from digital immigrants, there are additional variables that can help in understanding children's usage of digital media. The literature shows that despite digital skills of members of the young generation, their digital competencies are at times lower than those of their 
elders (Gallardo-Echenique et al., 2015). As opposed to the concept "digital native", the expression "digital learners" refers generically to all terms that attempt to differentiate sub-groups based on their digital literacy. This alternative concept assumes that the current generation of learners is profoundly affected by digital technologies (Romero et al., 2011). These are also referred to as "learners of the digital era", suggesting that age in itself is not the sole factor to be considered when addressing gap issues (Rapetti \& Cantoni, 2013). According to this term, the focus is on the person/community, and the perspective is anthropological-pedagogical, hence the focus on learning.

Digital equity and intercultural education concern education systems worldwide in the digital era. Accessibility issues, digital literacy and the nature of education systems attempting to adapt to digital culture - all these have bearing on possible opportunities of children and young adults to adjust themselves to novelties, and to society at large - to educate within intercultural and intergenerational contexts (Resta \& Laferrière, 2015). In this respect, educators, whether parents and families, or educational institutes, serve as agents for global, cultural, political, economic and social changes. Intercultural education may promote understanding of cultures across the globe. This in turn broadens opportunities for intercultural communication, tolerance and empathy, a growing field of practice and research. This challenge of equity addresses the need to better understand intergenerational and intercultural gaps, via extensive research and visibility on the ways in which the required competencies are achieved. Hence, the global society should encourage ICT usage in a ubiquitous and extensive manner, thereby moving towards stability and competency, i.e. technology as an integral component in everyday life and an extension of human capabilities (Alper, Katz \& Clark, 2016). In order to achieve this, there is a need to construct resources for different cultures and generations, with special attention to language and behaviors in social media (e.g., in Italy culturally responsive teaching is utilized for enhancing multicultural competencies).

In addition, development of means of intercultural communication and translation systems is vital, and may broaden possibilities to connect worldwide (Neuliep, 2017). This may be supported by common intercultural and generational activities via common projects, developed by government agencies, NGOs, or private 
entities, allowing data collection by electronic means and distribution of best practices for upbringing and education (formal and informal).

\section{Challenge 3: Upbringing in a technological world as a continuum: developing norms and conventions, and implications for education}

Homes are undoubtedly an important context for the growth and development of children and youth, and the basis for upbringing. Their interpersonal interaction develops during their first years at home, whereby values, attitudes, goals, and skills are passed on to the next generation. Studies focused on upbringing associate all these with developmental and social effects (Yuen et al., 2016).

The technological era allows continuous lifelong learning, beyond formal mandatory education; this is especially relevant in today's era of constant change and growth of information exponentially (Hanemann, 2015). Hence, upbringing in this context requires consideration of "the big picture", which means: creating a continuous manner in which upbringing is not defined by certain ages or groups within the population, but rather a comprehensive endeavor, encompassing all ages and sub-populations, and focusing on skills as well as engagement and awareness (Huda et al., 2017). Also, upbringing in this sense is not necessarily a pedagogical issue - it is an ongoing social, emotional, moral, cultural and behavioral undertaking (Tagunova, Selivanova \& Valeeva, 2016).

However, in spite of this comprehensive challenge, there is lack of research on development of digital culture as a continuum, globally and locally; therefore, sporadic attempts to construct continuous initiatives of development of norms across ages while acquiring ICT skills (e.g. Gamliel, 2017) are usually not evidence based on a wide national or international scale.

From birth, many young children's lives are immersed in multiple media (audio, video, printed and screen-based texts) and even very young children are experiencing the 21 st-century phenomenon of digital games and gaming. What is most interesting about contemporary media culture is not the participation in itself, but rather the productive-generated and performance-generated practices that the developments of digital media represent. These developments also raise questions of cultural competencies that are developed as part of such media 
culture. Jenkins et al., (2006) included creative designs, ethical considerations, and technical skills to capture youths' expressive and intellectual engagement with new media. As such, these developments in media practices point towards two important aspects: stimulating mobility and creativity among young people. Furthermore, these efforts to produce one's own media content have been associated with the growing do-it-yourself, or DIY, movement (Guzzetti, Elliott, \& Welsh, 2010; Lankshear \& Knobel, 2010).

One of the more recent developments taking place in relation to digital learning is the growth of 'makerspaces', and an NMC Horizon report suggests that they have "the potential to empower young people to become agents of change in their communities" (Johnson et al., 2015). The digital literacy and creative skills of young children is developed through participation in creative activities in specially-designed spaces termed 'makerspaces'. These are spaces that enable participants to create a range of artifacts using special tools and resources, such as electronics, laser cutters and 3D printers. There has been interest in recent years in the role of digital 'making', the design and production of digital artifacts, texts and products (Johnson et al., 2015) and the creation of fabrication labs, or 'makerspaces', in which children and young people use equipment such as 3D printers and laser cutters for these purposes (Blikstein, 2013). There is a need to enable young children to participate in such activities if they are to develop competences and dispositions that will inform their future study.

Peppler, Halverson, \& Kafai (in press) have pointed to the way in which much of the work on makerspaces to date has been focused on adolescents and adults and it is clear that certain demographic groups have been privileged in these projects, such as affluent groups and males (Blikstein \& Worsley, in press). Further, there has been little work on assessing and documenting students' work in makerspaces and minimal attention paid to matters of student engagement and learning. It is clear that there is much further research to be undertaken on the contribution that makerspaces can make to formal educational settings.

In an era of growing personalization, the awareness of the individual to different contexts in cyber-space is vital to his or her well-being (Jin, 2018); therefore, assistance throughout one's lifespan in continuous utilization of digital technologies that connect between the digital and the virtual is imperative. 
The SELFIE (self-assessment tool for digitally capable school) EU project is an example of these issues when referring to the education system. This is a reliable and validated self-assessment tool developed to assist schools in their utilization of digital technologies in learning activities and develop digital competence. This is achieved by an annual reflection of each school on its current utilization of digital technologies for innovative and effective learning and on desired improvement for the upcoming year. This self-assessment process is fully owned by the school, which may decide if and with whom to share its results (Fedeli, 2017). By this, children can also independently formulate criteria to determine the usefulness of a given technology.

\section{Challenge 4: Upbringing digital citizens as informed adults, experiencing well-being and security}

The term digital citizenship encompasses a broad range of activities and goals, including the ability to navigate within continuously expanding networks of information, to connect with communities, to engage in online and physical civic activities, to explore new possibilities for shared local and global initiatives, and to examine new ideas beyond traditional boundaries (Jones \& Mitchell, 2016). The continuously expanding infospace offers a new mode of citizenship, with additional and possibly novel perspectives and responsibilities that go beyond the local and national and require more global awareness, critical thinking and behavior, and even willingness to challenge ideas and values (Choi, Glassman \& Cristol, 2017).

Digital citizenship begins from a young age in the digital world. Children's lives are transformed by the flow of information and its result: connectivity worldwide, providing opportunities to actively engage as national and global citizens. Consequently, educators' roles on all levels of education, whether formal or informal, focus on the comprehension of the notion of global citizenship, which entails concepts such as respect for human rights, social justice, diversity, gender equality, and environmental sustainability (UNESCO, 2015). Moreover, in analyzing media use, especially during the last two decades, "digital migration" occurs, when young people migrate from traditional mass media towards digital media and between different online sites and mobile technologies, which create 
new patterns of use anytime, anywhere (Watkins, 2009). All this requires planning of opportunities for children to practice critical thinking related to the detailed issues, as well as to act in order to preserve the values of basic human rights in an attempt to make a difference (Bennett, Aguayo \& Field, 2016; Livingstone \& Third, 2017).

Digital media indeed influences civic engagement of youth (Cassell, Huffaker, Tversky, \& Ferriman, 2006; Selwyn, 2002). Young people use these online sites to express personal opinions, views, and comments, either through videos recorded at home, written text, or other means that are uploaded to shared spaces on the Internet. This implies a space where youngsters are part of the cultural flow of using different media and where they talk about themselves. (Lau \& Lee, 2015; Laurel, 1993; Turkle, 1995; Butler, 1997). Research shows that the Internet can serve as an information resource and community-building tool for civic engagement and political participation among young people (Rainie \& Horrigan, 2005). Therefore, the influence of the Internet on children and adolescents can perhaps play a positive role of engagement, a role that other institutions in society are no longer filling (Shin \& Lwin, 2017). These digital practices represent a challenge of participation and navigation in the Internet culture, exhibiting how competent young people are as democratic users and participants in navigating between online and offline spaces of importance to them (de Almeida, Delicado, de Almeida Alves, \& Carvalho, 2015).

Indeed, policymakers, researchers and practitioners need to consider a proper balance of utilizing digital technology for promoting children's rights. Research, consequently, is necessary for counteracting the contemporary popular tendency of anxiety regarding the risks of digital technologies and its allegedly negative effects. Controversial media coverage of this topic offers a dangerous viewpoint of technology, characterizing a type of technological determinism, e.g., technologies possessing intrinsic powers that affect all people in all situations similarly (Boyd, 2014). However, experiences of children and young people with digital media involve advantages as well as complexities. Complexity also characterizes the role of practitioners and researchers in their attempts to promote children's rights and allowing them to pursue these rights (Coppock \& GillettSwan, 2016). 
Notwithstanding, we know even less about digital citizenship and the conditions for this pursuit for children with disabilities. These children face challenges similar to those of other children. However, obstacles to their inclusion may intersect with additional traits (e.g., socio-cultural position, gender, religion, and geographic location). These pose challenges for all involved, firstly, teaching key literacies and ensuring full participation within societies so these populations do not remain out of reach (Alper \& Goggin, 2017).

Information technologies have greatly expanded the pace and extension of virtually all cultural operations and outcomes, and the landscape of opportunities

and agency for civic engagement have been greatly expanded (Erstad, 2016, Ito et al., 2013). However, these networked configurations do not only produce new opportunities, but also create "new differences, inequalities and forms of exclusion, or disconnections" (Tufte \& Enghel, 2009, p. 13). An important question, therefore, is to understand how today's different social and technological arrangements or contexts influence young people's norms, attitudes, values, and readiness to act towards issues of sustainability and inclusion.

The main focus of this challenge is twofold: to promote respectful behavior online and to encourage online civic engagement. This requires several initiatives within the community at large, not only in schools, as a means for ensuring best upbringing of future citizens that exhibit greater compassion and awareness (Schulz et al., 2016). An initial necessary step would be to educate the entire community about best uses of technology for the benefit of society, and strategies to identify malicious activities online. Appropriate technology usage and awareness of instances such as plagiarism, digital marketing and proper communication require digital competencies as well as moral and ethical values, and may require signing a pledge for better behavior online. Notwithstanding, educators within communities should promote critical thinking, which in turn requires understanding the digital culture (Tan, Chua \& Goh, 2015).

\section{Implications: Crossing boundaries}

Children are prone to exceed the limits through which they are formally taught and prepared for their future as productive citizens, contemplating about issues of concern, such as human rights, with ever greater intensity in the digital age (Gasser \& Cortesi, 2015). Although children are perceived as vulnerable and in 
need of protection, this notion strengthens the conception of young people not as an integral part of a wider digital entity. Yet, in digital media children from the age of schooling are able to speak their mind directly (Livingstone \& Third, 2017).

Contemporary research addresses experiences of pre-school children with digital technologies that shape their communicative and creative practices (Fridin, 2014; Hsin, Li \& Tsai, 2014; Sharkins et al., 2016; Sundqvist \& Nilsson, 2016). Studies conclude that digital technologies have the potential to expand young children's communicative and creative skills and competencies, thereby broadening their abilities to create a borderless global culture. Mediated experiences with technologies have significant implications for early childhood education; hence, practitioners are asked to rely on technology-based experiences of children from their homes. This implies the need to modify the home environment as a result of the growing presence of digital technologies, and in accordance - the nature of children's experiences and their subsequent practices. The competences children develop prior to their formal learning are valuable for their schooling period. Children attending pre-school and primary education grow up in homes enriched with multimedia, digital and diverse forms of communication via digital technologies. Hence, global policy should highlight the importance of further developing these experiences in formal education (McPake, Plowman \& Stephen, 2013).

Given the mobility afforded by technology such as smart phones and tablets, texts are produced and read across a range of spaces, and this has brought about profound changes in everyday literacy practices. The implications of these significant changes for young children's digital literacy development need to be urgently addressed. The changes in everyday literacy practices brought about by the miniaturization, mobility, personalization and ubiquitous use of digital technologies are as profound as the changes brought about by the invention of the printing press (Kress, 2003). Statistics about changing media use from analogue to digital, and about how digital media are often central to children's everyday interactions with the world, do suggest a change in the way that children experience their literacy lives in contrast with previous generations. In her presidential address to the American Educational Research Association, called "Learning in School and Out," Lauren Resnick (1987) considered where 
and how the economic, civic, and cultural aims of education can best be pursued and whether schooling itself should be reorganized to take account of what we are learning about the nature of competence in various aspects of our lives. (p. 13). She went on to discuss how school learning differs from other learning, practical from formal intelligence. She was trying to address some of the core questions that seem to have gotten lost today about characteristics of learning in and out of school and how these change over time. However, her ambition was to show how life in and out of school differs in certain categories, rather than looking at how they connect. Our argument is that these divisions are more blurred now than ever before, especially from the learners' point of view, and that we need to redefine how we understand these interrelationships between contexts.

\section{Recommendations to policymakers, researchers and practitioners}

In light of the challenges for upbringing in the digital world, we suggest some recommendations that are possibly intertwined and interrelated. At large, we suggest joint top-down and bottom-up initiatives. Policymakers should establish a holistic, interconnectedness policy, based on evidence-based findings. Policy should promote family, school and the community involvement in upbringing of the young generation. They are expected to construct environments for intergenerational and inter-cultural collaboration projects, but also to establish regulations, thereby voicing all stakeholders involved. This may lead to developing longitudinal guidelines for digital competencies in cultural and intercultural contexts, e.g., funding of digital citizenship programs and projects.

Researchers should examine the effectiveness of diverse technologies in alternative community structures, and study the benefits of holistic approaches to upbringing. This should take into account multi-disciplinary, inter-generational and inter-cultural issues, development of digital culture as a continuum worldwide, as well as tools for promoting digital citizenship.

Practitioners can raise awareness for upbringing in the digital age by implementing digital tools and facilitating community events that involve parents, teachers and community members and encourage and support an ecological perspective of upbringing. They should construct and use global open databases with examples of best practice scenarios for upbringing, and initiate projects 
which involve collecting worldwide data, and create and implement initiatives that promote a lifelong learning progressive approach. This can take the form of courses and workshops (physical and online) for parents, teachers, and community members, as well as populations with special needs. The goal of these is preserving well-being in an ICT saturated environment.

Acknowledgement. The authors wish to acknowledge the contribution of Thematic Working Group (TWG) 8 participants in EDUsummIT 2017: Vadim Grinshkun and Sergey Grigoryev (Moscow City University, Russian Federation), Alexander Khoroshilov (Russian Federation), Eugenia Kovatcheva (University of Library Studies \& Information Technologies, Bulgaria) and Jasmine Amor (Cambodia Foundation for Higher Education, USA).

\section{References}

Alper, M. (2013). Developmentally appropriate new media literacies: Supporting cultural competencies and social skills in early childhood education. Journal of Early Childhood Literacy, 13(2), 175-196.

Alper, M., \& Goggin, G. (2017). Digital technology and rights in the lives of children with disabilities. New Media \& Society, 19(5), 726-740.

Alper, M., Katz V. S., \& \& Clark, L. S. (2016). Researching children, intersectionality, and diversity in the digital age. Journal of Children and Media, 10(1), 107-114.

Arnott, L. (2013). Are We Allowed to Blink? Young Children's Leadership and Ownership While Mediating Interactions around Technologies. International Journal of Early Years Education, 21, 97-115.

Arnott, L. (2016). An ecological exploration of young children's digital play: framing children's social experiences with technologies in early childhood. Early Years, 36(3), 271-288.

Aubrey, C., \& Dahl, S. (2014). The confidence and competence in information and communication technologies of practitioners, parents and young children in the Early Years Foundation Stage.

Early years, 34(1), 94-108.

Barnyak, N., \& McNelly, T. (2015). Supporting young children's visual literacy through the use of ebooks. In K. Heider \& M. Jalongo (Eds.), Young children and families in the information age:

Applications of technology in early childhood (pp. 15-43). Netherlands: Springer.

Bennett, L. B., Aguayo, R. C., \& Field, S. L. (2016). At Home in the World: Supporting Children in Human Rights, Global Citizenship, and Digital Citizenship. Childhood Education, 92(3), 189-199. Blikstein, P. (2013). Digital fabrication and 'making' in education: The democratization of invention. In J. Walter-Hermann \& C. Buching (Eds.), Fab Labs: Of machines, makers and inventors. Bielefeld: Transcript Publishers. Retrieved from https://tltl.stanford.edu/sites/default/files/files/documents/publications/2013.Book- B.Digital.pdf Blikstein, P. \& Worsley, M. (in press). The Maker Movement: The last chance of progressive education? In Peppler, K., Halverson, E. \& Kafai, Y. (Eds.) Makeology: Makerspaces as learning environments (Volume 1). New York, NY: Routledge.

Bond, E. (2014). Childhood, Mobile Technologies and Everyday Experiences: Changing technologies = changing childhoods? (pp. 41-69). London: Palgrave Macmillan.

Boyd, d. (2014). It's Complicated: the social lives of networked teens. London: Yale University Press. Buitrago Flórez, F., Casallas, R., Hernández, M., Reyes, A., Restrepo, S., \& Danies, G. (2017).

Changing a generation's way of thinking: Teaching computational thinking through programming. Review of Educational Research, 87(4), 834 - 860.

Butler, J. (1997). Excitable speech: A politics of the performative (pp. 43-70). New York, NY: Routledge.

Cambridge English Dictionary (2018). Cambridge Dictionaries Online. Cambridge University Press, Cambridge, UK. Retrieved from https://dictionary.cambridge.org/

Cassell, J., Huffaker, D., Tversky, D., \& Ferriman, K. (2006). The language of online leadership: Gender and youth engagement on the Internet. Developmental Psychology, 42(3), 436-449. 
Choi, M., Glassman, M., \& Cristol, D. (2017). What it means to be a citizen in the internet age:

Development of a reliable and valid digital citizenship scale. Computers \& Education, 107, 100-112.

Coppock, V., \& Gillett-Swan, J. K. (2016). Children's rights in a 21st-century digital world:' Exploring opportunities and tensions. Global Studies of Childhood, 6(4) 369-375.

Damásio, M. J., Henriques, S., Teixeira-Botelho, I., \& Dias, P. (2015). Mobile Media and Social Interaction: Mobile Services and Content as Drivers of Social Interaction. In Aguado, J. M., Feijóo, C., \& Martínez, I. J. (Eds.), Emerging Perspectives on the Mobile Content Evolution (pages 357-379). PA: IGI Global.

de Almeida, A. N., Delicado, A., de Almeida Alves, N., \& Carvalho, T. (2015). Internet, children and space: Revisiting generational attributes and boundaries. New media \& society, 17(9), 1436-1453. Donald, M. (2014). The Digital Era: Challenges for the Modern Mind. CADMUS, 2(2), 68-79. Druin A. (2009). Introduction: Defining mobile technologies, children, and learning. In, A Druin, (Ed.) Mobile Technology for Children: Designing for Interaction and Learning (pp. 3-22).

Amsterdam: Morgan Kauffman.

Elkin, M., Sullivan, A., \& Bers, M.U. (2014). Implementing a robotics curriculum in an early childhood Montessori classroom. Journal of Information Technology Education: Innovations in Practice, 13, 153-169.

Encyclopedia.com (2018). The Oxford Pocket Dictionary of Current English, originally published by Oxford University Press. Retrieved from https://www.encyclopedia.com

Erstad, O. (2016). Agentive students using social media - Spatial positionings and engagement in Space2cre8. In, M. Walrave, K. Ponnet,E. Vanderhoven, J. Haers \& B. Segaert (ed.), Youth 2.0: Social media and adolescence. Connecting, sharing and empowering (pp. 79-102). Switzerland: Springer Publishing Company.

Fedeli, L. (2017). School, curriculum and technology: the what and how of their connections. Education Sciences \& Society, 8(2), 42-50.

Fox, J.L, \& Diezmann, C.M. (2017). The Australian Early Years Leaning Framework and ICT: A Part of Life or Apart from Life? In, M. Li, J.L., Fox, \& S. Grieshaber, Contemporary Issues and Challenges in Early Childhood Education in the Asia-Pacific Region (pp. 143-164). Singapore: Springer Nature. Fridin, M. (2014). Storytelling by a kindergarten social assistive robot: A tool for constructive learning in preschool education. Computers \& Education, 70, 53-64.

Gallardo-Echenique, E. E., Marqués-Molías, L., Bullen, M., \& Strijbos, J. W. (2015). Let's talk about digital learners in the digital era. The International Review of research in open and distributed learning, 16(3), 156-187.

Gamliel, T. (2017). Education in civic participation: Children, seniors and the challenges of an intergenerational information and communications technology program. New Media \& Society, 19(9), 1388-1405.

Gasser, U., \& Cortesi, S. C. (2015). Digitally Connected: Global Perspectives on Youth and Digital Media. MA: Harvard, Berkman Center, Research Publication No. 2015-6.

Grigorev, S.G., Grinshkun, V.V., \& Lvova, O.V. (2014). Some aspects of education informatization in Russia concerning training future teachers. Bulletin of Peoples' Friendship University of Russia, 3, 14-18.

Guzzetti, B., Elliott, K., \& Welsch D. (2010). DIY media in the classroom: New literacies across content areas. New York, NY: Teachers College Press.

Hanemann, U. (2015). Lifelong literacy: Some trends and issues in conceptualising and operationalising literacy from a lifelong learning perspective. International Review of Education, 61(3), 295-326.

Hershkovitz, A., \& Forkosh-Baruch, A. (2017). Teacher-Student Relationship and FacebookMediated Communication: Student Perceptions. Comunicar, 25(53), 91-100.

Holloway, D., Green, L. \& Livingstone, S. (2013). Zero to Eight. Young children and their Internet use. LSE, London: EU Kids Online.

Hsin, C. T., Li, M. C., \& Tsai, C. C. (2014). The influence of young children's use of technology on their learning: A. Educational Technology \& Society, 17(4), 85-99.

Huda, M., Jasmi, K. A., Basiron, B., Hehsan, A., \& Gassama, S. K. (2017). Empowering children with adaptive technology skills: careful engagement in the digital information age. International Electronic Journal of Elementary Education, 9(3), 693-708. 
Ito, M., Gutiérrez, K., Livingstone, S., Penuel, B., Rhodes, J., Salen, K., Schor, J., Sefton-Green, J. \& Craig Watkins, S. (2013). Connected learning. An agenda for research and design. Accessed July 2017 at: https://dmlhub.net/wp-content/uploads/files/Connected Learning report.pdf Jenkins, H., Clinton, K., Purushotma, R., Robinson, A. J., \& Weigel, M. (2006). Confronting the challenges of participatory culture: Media education for the 21st century. An occasional paper written for the MacArthur Foundation.

Jin, C. H. (2018). Self-concepts in cyber censorship awareness and privacy risk perceptions: What do cyber asylum-seekers have? Computers in Human Behavior, 80, 379-389.

Johnson, L., Adams Becker, S., Estrada, V., and Freeman, A. (2015). NMC Horizon Report: 2015 K12 Edition. Austin, Texas: The New Media Consortium. Retrieved from:

http://cdn.nmc.org/media/2015-nmc-horizon-report-k12-EN.pdf

Jones, L. M., \& Mitchell, K. J. (2016). Defining and measuring youth digital citizenship. New media \& society, 18(9), 2063-2079.

Kaufman, K. J. (2013). 21 ways to 21st century skills: why students need them and ideas for practical implementation. Kappa Delta Pi Record, 49(2), 78-83.

Kress, G. (2003). Literacy in the new media age. London, England: Routledge.

Lankshear, C., \& Knobel, M. (Eds.). (2010). DIY media. Creating, sharing and learning with new technologies. New York, NY: Peter Lang.

Lau, K. W., \& Lee, P. Y. (2015). The use of virtual reality for creating unusual environmental stimulation to motivate students to explore creative ideas. Interactive Learning Environments, 23(1), 3-18.

Laurel, B. (1993). Computers as theatre. Reading, MA: Addison-Wesley.

Levin, D., Arafeh, S., \& Rainie-Director, L. (2002). The digital disconnect. Pew Internet and American Life Project. US: Washington, DC.

Livingstone, S. (2004). Media literacy and the challenge of new information and communication technologies. The Communication Review, 7(1), 3-14.

Livingstone, S., \& Third, A. (2017). Children and young people's rights in the digital age: An emerging agenda. New Media \& Society, 19(5), $657-670$.

Marsh, J. (2015). Research technologies in children's worlds and futures. In A. Farrell, S.L. Kage, K. Tidsall (eds), Sage Handbook of Early Childhood Research. (pp485-501). London. Sage.

Marsh, J., Plowman, L., Yamada-Rice, D., Bishop, J.C., Lahmar, J., Scott, F., Davenport, A., Davis, S., French, K., Piras, M., Thornhill, S., Robinson, P. and Winter, P. (2015) Exploring Play and Creativity in Pre-Schoolers' Use of Apps: Final Project Report. [Accessed: www.techandplay.org]

Marsh, J., Mascheroni, G., Carrington, V., Árnadóttir, H., Brito, R., Dias, P., Kupiainen, R., \& Trueltzsch-Wijnen, C. (2016). The Online and Offline Digital Literacy Practices of Young Children. Accessed July 2017 at: http://digilitey.eu/wp-content/uploads/2017/01/WG4-LR-jan-2017.pdf Mayerové, K., \& Veselovská, M. (2017). How to teach with LEGO WeDo at primary school. In, M., Merdan, W., Lepuschitz, G., Koppensteiner, \& R., Balogh (eds), Robotics in Education (pp. 55-62). Switzerland: Springer International Publishing.

Merchant, G., Gillen, J., Marsh, J. \& Davies (eds.) (2013). Virtual literacies. Interactive spaces for children and young people. New York: Routledge.

Neuliep, J. W. (2017). Intercultural communication: A contextual approach (7th ed.) (pp. 2-43). CA: Sage Publications.

Peppler, K., Halverson, E. \& Kafai, Y. (Eds.) (in press). Makeology: Makerspaces as learning environments (Volume 1 and 2). New York, NY: Routledge.

Pinto-Llorente, A. M., Casillas-Martín, S., Cabezas-González, M., \& García-Peñalvo, F. J. (2017). Building, coding and programming 3D models via a visual programming environment. Quality \& Quantity, 1-14. DOI: 10.1007/s11135-017-0509-4

Plowman, L. (2015). Researching Young Children's Everyday Uses of Technology in the Family Home. Interacting with Computers, 27, 36-46.

Plowman, L. (2016). Rethinking context: Digital technologies and children's everyday lives. Children's Geographies, 14(2), 190-202

Plowman L., Stevenson O., Stephen C., \& McPake J. (2012) Preschool children's learning with technology at home. Computers \& Education, 59(1) 30-37.

Prensky, M. (2001). Digital natives, digital immigrants: part 1. On the horizon, 9(5), 1-6. Rainie, L., \& Horrigan, J. (2005). A decade of adoption: How the Internet has woven itself into American life. Washington, DC: PEW Internet and Family Life. 
Rapetti, E., \& Cantoni, L. (2013). Reconsidering "Gen Y" \& Co: From minding the gap to overcoming it. The European Journal of Open, Distance and E-Learning - EURODL, 16(2), 1-13.

Resnick, L. (1987). Learning in school and out. Educational Researcher, 16, 3-21.

Resta, P., \& Laferrière, T. (2015). Digital equity and intercultural education. Education and Information Technologies, 20(4), 743-756.

Romero, M., Guitert, M., Bullen, M., \& Morgan, T. (2011). Learning in digital: An approach to digital learners in the UOC scenario. European Journal of Open, Distance and E-Learning, 14(2)1-8. Schulz, W., Ainley, J., Fraillon, J., Losito, B., \& Agrusti, G. (2016). IEA international civic and citizenship education study 2016 assessment framework. Australia: Australian Council for Educational Research (ACER)/Netherland: IEA.

Selwyn, N. (2002). Literature review in citizenship, technology and learning. Bristol, England: Nesta Futurelab.

Sefton-Green, J., Marsh, J., Erstad, O. \& Flewitt, R. (2016). Establishing a Research Agenda for the Digital Literacy Practices of Young Children A White Paper for COST Action IS1410. Accessed July 2017 at: http://digilitey.eu/wp-content/uploads/2015/09/DigiLitEYWP.pdf

Sharkins, K. A., Newton, A. B., Albaiz, N. E. A., \& Ernest, J. M. (2016). Preschool children's exposure to media, technology, and screen time: Perspectives of caregivers from three early childcare settings. Early Childhood Education Journal, 44(5), 437-444.

Shin, W., \& Lwin, M. O. (2017). How does "talking about the Internet with others" affect teenagers' experience of online risks? The role of active mediation by parents, peers, and school teachers. New Media \& Society, 19(7), 1109-1126.

Siraj-Blatchford, J., \& Brock, L. (2016) Early Childhood Digital Play and the Zone of Proximal Developmental Flow (ZPDF). In, Proceedings Congreso I nternacional de Innovacion Y Tecnologia Educativa en Educacion Infantil. Seville, Spain.

Sundqvist, P., \& Nilsson, T. (2016). Technology education in preschool: providing opportunities for children to use artifacts and to create. International Journal of Technology and Design Education, 1, 1-23. DOI: 10.1007/s10798-016-9375-y

Tagunova, I. A., Selivanova, N. L., \& Valeeva, R. A. (2016). The category of upbringing in Russian and western studies. Mathematics Education, 11(1), 3-11.

Terreni, L. (2010). Adding New Possibilities for Visual Art Education in Early Childhood Settings: The Potential of Interactive Whiteboards and ICT. Australasian Journal of Early Childhood, 35(4), 90-94. Turkle, S. (1995). Life on the screen: Identity in the age of the Internet. New York, NY: Simon and Schuster.

UNESCO (2015). Global citizenship education. Accessed July 2017 at:

http://www.unesco.org/hew/en/global-citizenship-education

Vasb $\varnothing$, K. B., Silseth, K. \& Erstad, O. (2014). Being a Learner Using Social Media in School: The Case of Space2cre8. Scandinavian Journal of Educational Research, 58(1), s 110- 126

Voogt, J., Erstad, O., Dede, C., \& Mishra, P. (2013). Challenges to learning and schooling in the digital networked world of the 21st century. Journal of computer assisted learning, 29(5), 403-413. Watkins, C. S. (2009). The young \& the digital: What the migration to social-network sites, games, and anytime, anywhere media means for our future. Boston, MA: Beacon Press.

Yuen, A. H., Park, J., Chen, L., \& Cheng, M. (2016). The significance of cultural capital and parental mediation for digital inequity. New Media \& Society. DOI: 10.1177/1461444816667084 